\title{
Synthesis of Co Filled Carbon Nanotubes by In Situ Reduction of $\mathrm{CoCl}_{2}$ Filled Nanotubes by $\mathrm{NaBH}_{4}$
}

\author{
J. Mittal \\ Amity Institute of Nanotechnology, Amity University, Sector 125, Noida, 201313 UP, India \\ Correspondence should be addressed to J. Mittal; jagjiwanmittal@gmail.com
}

Received 13 May 2013; Accepted 13 June 2013

Academic Editors: V. Baranauskas and S. X. Dou

Copyright (C) 2013 J. Mittal. This is an open access article distributed under the Creative Commons Attribution License, which permits unrestricted use, distribution, and reproduction in any medium, provided the original work is properly cited.

\begin{abstract}
An alternative process of filling the multiwall nanotubes (MWCNTs) with cobalt metal was developed. Empty core of nanotubes was first filled with $\mathrm{CoCl}_{2}$ by stirring with $\mathrm{CoCl}_{2}$ and alcohol at room temperature for six hours. $\mathrm{CoCl}_{2}$ filling inside MWCNTs was then converted into Co after treating with $\mathrm{NaBH}_{4}$ at room temperature. High resolution transmission electron microscope (HRTEM) studies showed the filling of the $\mathrm{CoCl}_{2}$ and $\mathrm{Co}$ inside the nanotubes before and after the treatment. EDX studies show the nonexistence of chlorine after the reduction with $\mathrm{NaBH}_{4}$. Amount of filling was also reduced after the treatment. Paper describes the possible mechanism of filling $\mathrm{CoCl}_{2}$ inside nanotube and its reduction by $\mathrm{NaBH}_{4}$.
\end{abstract}

\section{Introduction}

Exceptional properties of carbon nanotubes, like high strength, discrete electronic states, and so forth, make them highly suitable for the applications in nanodevices. They are the most appropriate material for using in devices like AFM probes [1], FE transistors [2,3] display devices [4-6], and so forth. Filling of carbon nanotubes with materials enhances their physical and chemical properties and their potential applications in different areas [7-9]. They show interesting physical and structural properties which are different than their parent materials $[7,10]$.

Magnetic metal nanoparticles (such as $\mathrm{Fe}, \mathrm{Co}$, and $\mathrm{Ni}$ ) have applications such as high-density magnetic data storage, magnetic separation of biomolecules, and treatment of cancer $[11,12]$. However, the poor oxidation resistance of the metal nanoparticles is a great hindrance for their applications. Encapsulation of nanoparticles in carbon nanotubes may be highly useful with the combination of properties of magnetic nanoparticles and carbon nanotubes [13-16]. Ferromagnetic metals filled carbon nanotubes have significant potential in data storage technology [17]. Additionally, the walls of carbon nanotubes provide an effective shelter against oxidation of magnetic nanoparticles and thus ensure a long-term stability of the ferromagnetic core [17].
Various methods are employed for the filling of carbon nanotubes, such as arc discharge $[18,19]$, high-temperature heat treatment [20], capillary induced [21], ion-beam sputtering [22], and chemical vapor deposition (CVD) [23, 24]. Although arc discharge technique is a better method, low yield is a problem for commercial applications. CVD method is a simple and low cost method and can produce filled carbon nanotubes in large quantities. However, all these methods are the in situ synthesis of metal filled nanotubes. There are very few studies for the filling the CNTs using after their preparation $[9,10]$. The present paper describes an easy method of the filling of the carbon nanotubes using first $\mathrm{CoCl}_{2}$ and then reducing the $\mathrm{CoCl}_{2}$ into Co using $\mathrm{NaBH}_{4}$.

\section{Materials and Methods}

MWCNTs obtained from ASI, open from both ends, having a diameter in the range from 150 to $200 \mathrm{~nm}$, were taken in a flask and mixed with $\mathrm{CoCl}_{2}$ in alcohol in equal molar ratio. The mixture was stirred for 6 hours at room temperature in air. After stirring, the sample was washed with alcohol for the removal of unreacted $\mathrm{CoCl}_{2}$. $\mathrm{CoCl}_{2}$ filled MWCNTs were then mixed with $\mathrm{NaBH}_{4}$ in alcohol, and the mixture was cooled down to $273 \mathrm{~K}$. The reaction between $\mathrm{CoCl}_{2}$ filled MWCNTs and $\mathrm{NaBH}_{4}$ was carried out in inert atmosphere of 


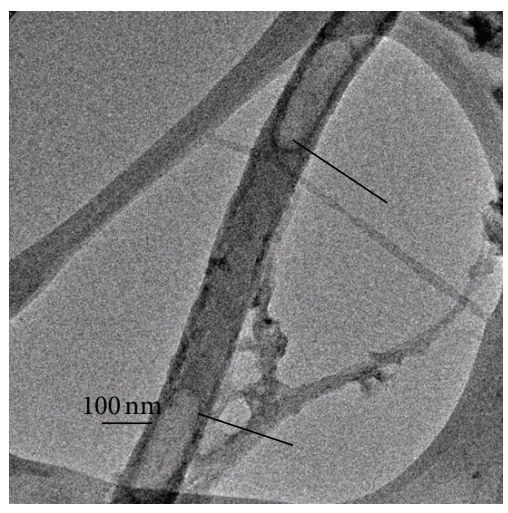

(a)

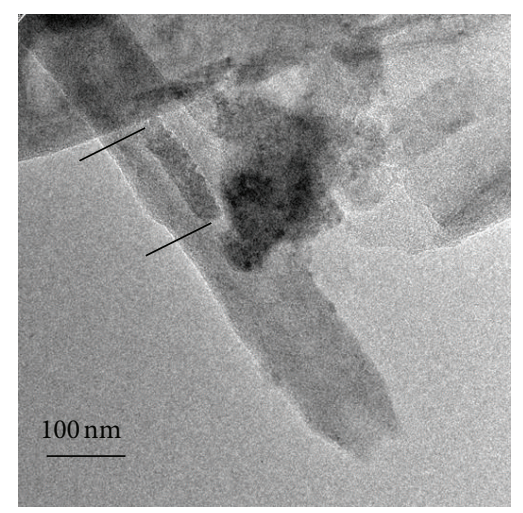

(b)

FIGURE 1: HRTEM micrographs showing the (a) and (b) $\mathrm{CoCl}_{2}$ filled nanotubes in low magnifications where the filling appears darker than the empty part in the hole of the nanotubes.

argon. The mixture was then stirred for 6 hours. Once the treatment time were over, nanotubes were taken out from flask, washed with alcohol, and characterized.

Structural investigation of the products was done using high resolution transmission electron microscope (HRTEM) operating at $150 \mathrm{KVa}$ with a point resolution of $3 \AA$. Contrast was enhanced by adding an $8 \mathrm{~nm}$ large aperture in the back focal plane on the objective lens. Electron dispersive X-ray spectroscopy was used to characterize the elemental analysis.

\section{Results and Discussion}

3.1. $\mathrm{CoCl}_{2}$ Filled Multiwalled Nanotubes. HRTEM micrographs in Figures 1(a) and 1(b) demonstrate two MWCNTs after stirring with $\mathrm{CoCl}_{2}$. Some part of the central hole of nanotubes, shown between two lines, is observed to be darker than the nanotube walls. This dark material is the filling inside the empty core of the nanotubes. Filling appears darker than the nanotubes walls whereas the empty hole appears lighter than the walls. Core of nanotube is observed to be filled at few places whereas other places are seen empty. Material is not filled throughout the nanotube hole. Filling is dense in Figure 1(b) whereas it is slightly transparent in Figure 1(a). This transparency may be due to the entrance of liquid in the nanotubes.

High magnification study in Figure 2(a) shows that some part of the filling is dense, and there is some crystalline nature in the filled material. The filling covers the entire width of the hole. Graphene layers of nanotube walls remain intact. There is no effect of the treatment on the nanotube walls.

Figure 2(b) shows EDX study of the filled material in Figure 2(a). Analysis demonstrates the presence of $\mathrm{Cu}, \mathrm{Co}$, and $\mathrm{Cl}$ in the filling. Since $\mathrm{Cu}$ grids are used for the study, observed $\mathrm{Cu}$ is due to the grid. Existence of $\mathrm{Co}$ and $\mathrm{Cl}$ indicates the presence of $\mathrm{CoCl}_{2}$.

3.2. Co Filled Multiwalled Nanotubes. Figure 3(a) shows a $\mathrm{CoCl}_{2}$ filled nanotube after treatment with $\mathrm{NaBH}_{4}$. A quadrilateral size particle of dimensions $100 \times 60 \mathrm{~nm}$ is observed inside the nanotube. Nanoparticle covers the width of the nanotube. However, a slight gap appeared on the both sides between the nanotube wall and nanoparticles. This gap is not visible in the $\mathrm{CoCl}_{2}$ filled nanotubes (Figure 2(a)).

EDX study in the Figure 3(b) shows the presence of Co. No existence of $\mathrm{Cl}$ is observed in the filling. Reduction in size shows the removal of chlorine from the filling $\mathrm{CoCl}_{2}$. The nanoparticle is not as dense as the $\mathrm{CoCl}_{2}$. Some part is dense whereas the other part is hollow which may be due to the removal of $\mathrm{Cl}$ from the inside of crystalline $\mathrm{CoCl}_{2}$.

3.3. Mechanism of the Filling of $\mathrm{CoCl}_{2}$ and Reduction with $\mathrm{NaBH}_{4}$. Illustration in Figure 4 depicts the complete process of filling Co metal in multiwalled nanotube. Step 1 of the process is the stirring of nanotubes with $\mathrm{CoCl}_{2}$ in alcohol at room temperature in air for six hours. Since the nanotubes used are already open, $\mathrm{CoCl}_{2}$ along with alcohol enters in the empty hole of the nanotubes due to the capillary effect. This leads to the formation of $\mathrm{CoCl}_{2}$ filled MWCNTs $\left(\mathrm{CoCl}_{2} @ \mathrm{MWNT}\right)$, as shown by the following reaction:

$$
\underset{(\text { open })}{\mathrm{MWNT}}+\mathrm{CoCl}_{2}+\text { Alcohol } \underset{\text { Air, RT }}{\stackrel{\text { Stirring }}{\longrightarrow}} \mathrm{CoCl}_{2} @ \mathrm{MWCNTs}
$$

In the second step, $\mathrm{CoCl}_{2}$ MWNTs are treated with $\mathrm{NaBH}_{4}$ in ethyl alcohol at $273 \mathrm{~K}$ in argon atmosphere. This treatment converts $\mathrm{CoCl}_{2} @ \mathrm{MWCNTs}$ into Co@MWCNTs with $\mathrm{NaBH}_{4}$, and $\mathrm{CoCl}_{2}$ get reduced to the Co, as shown in the following reaction:

$$
\mathrm{CoCl}_{2} @ \mathrm{MWNTs}+\mathrm{NaBH}_{4}+\text { Alcohol } \underset{\text { Stirring }}{\stackrel{0}{\circ} \mathrm{C}, \mathrm{Ar}} \mathrm{Co@MWNTs}
$$

$\mathrm{NaBH}_{4}$ is a reducing agent and better known for the reduction of the aldehydes and acids in the organic chemistry. Besides these, it is also used for reducing metal chlorides into metals $[25,26]$. Absence of chlorine in the EDX analysis of Co metal in Figure 3 indicates the reduction of $\mathrm{CoCl}_{2} \cdot \mathrm{NaBH}_{4}$ may also form the $\mathrm{CoB}_{2}$ during the reduction [25], as observed in the 


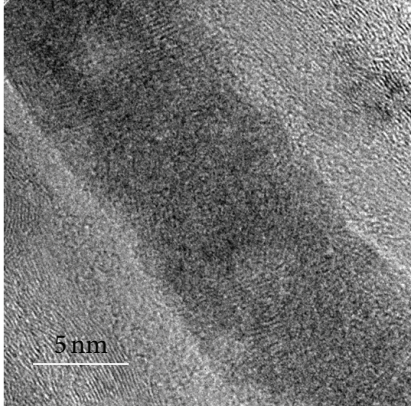

(a)

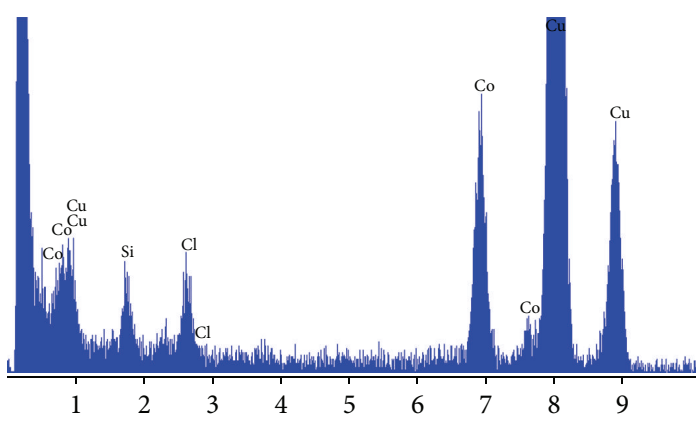

(b)

FIGURE 2: (a) HRTEM micrographs showing crystallized $\mathrm{CoCl}_{2}$ in the hole of nanotube, (b) EDX analysis showing the presence of Co and $\mathrm{Cl}$ in the filling material inside the nanotube. This indicates the presence of $\mathrm{CoCl}_{2}$ inside the empty core of the nanotube.

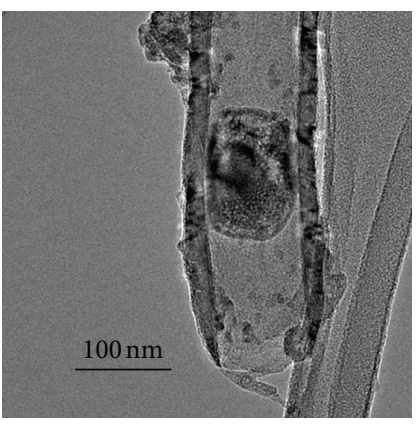

(a)

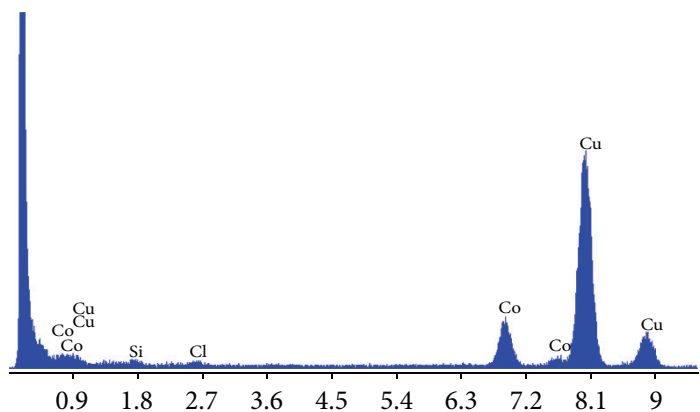

(b)

FIgURE 3: (a) TEM micrographs showing the Co nanoparticle in the nanotube, (b) EDX study of the Co nanoparticle showing the absence of $\mathrm{Cl}$. $\mathrm{Cu}$ is from the grid used in TEM.
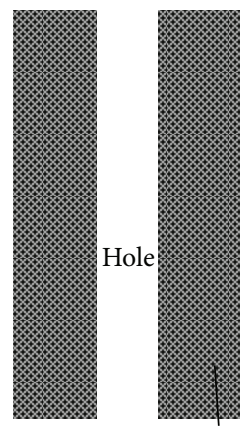

Graphenes
(1) $\mathrm{CoCl}_{2}+$ $\underset{\text { alcohol }}{\stackrel{\text { Stiring }}{\longrightarrow}}$ Stirring

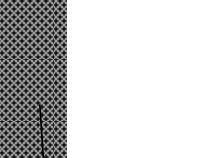

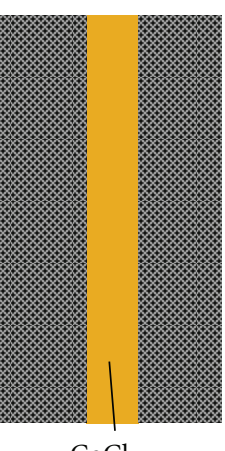

$\mathrm{CoCl}_{2}$
(2)

$\mathrm{NaBH}_{4}+$ $\stackrel{\text { alcohol }}{\longrightarrow}$ Stirring $273 \mathrm{~K}$

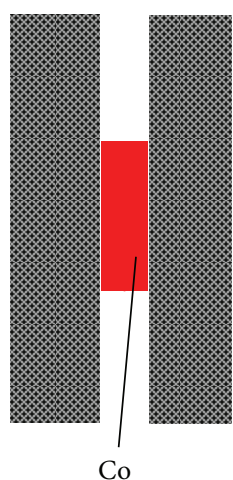

FIgure 4: Illustrations showing the (1) filling of $\mathrm{CoCl}_{2}$ inside the nanotubes, (2) conversion of $\mathrm{CoCl}_{2}$ into Co inside the nanotubes by $\mathrm{NaBH}_{4}$.

earlier studies where water was used as a solvent. However, EDX analyses of Co metal in Figure 3 show the nonexistence of boron and oxygen. This shows that the conditions of the reaction (2) are not suitable for forming the $\mathrm{CoB}_{2}$ or $\mathrm{Co}_{2} \mathrm{O}_{3}$ and lead to the formation of pure Co metal inside the nanotube.

\section{Conclusions}

$\mathrm{CoCl}_{2}$ was successfully filled inside the multiwalled nanotubes after stirring both in alcohol for six hours. $\mathrm{CoCl}_{2}$ inside the nanotube is converted into Co by $\mathrm{NaBH}_{4}$ using alcohol as a solvent. Absence of chlorine, boron, and oxygen in the EDX study shows the formation of pure Co inside the nanotubes.

\section{Acknowledgments}

The author is thankful for Dr. A. K. Chauhan, founder president, Amity University, Dr. R. P. Singh, Advisor, and Tinku Basu, Head, Amity Institute of Nanotechnology, Amity University, for their help in publishing this work. 


\section{References}

[1] H. Dai, J. H. Hafner, A. G. Rinzler, D. T. Colbert, and R. E. Smalley, "Nanotubes as nanoprobes in scanning probe microscopy," Nature, vol. 384, no. 6605, pp. 147-150, 1996.

[2] S. J. Tans, A. R. M. Verschueren, and C. Dekker, "Roomtemperature transistor based on a single carbon nanotube," Nature, vol. 393, no. 6680, pp. 49-52, 1998.

[3] P. G. Collins, A. Zettl, H. Bando, A. Thess, and R. E. Smalley, "Nanotube nanodevice," Science, vol. 278, no. 5335, pp. 100-102, 1997.

[4] W. A. De Heer, A. Châtelain, and D. Ugarte, "A carbon nanotube field-emission electron source," Science, vol. 270, no. 5239, pp. 1179-1180, 1995.

[5] S. Fan, M. G. Chapline, N. R. Franklin, T. W. Tombler, A. M. Cassell, and H. Dai, "Self-oriented regular arrays of carbon nanotubes and their field emission properties," Science, vol. 283, no. 5401, pp. 512-514, 1999.

[6] M. A. Burns, B. N. Johnson, S. N. Brahmasandra et al., "An integrated nanoliter DNA analysis device," Science, vol. 282, no. 5388, pp. 484-487, 1998.

[7] M. Monthioux, "Filling single-wall carbon nanotubes," Carbon, vol. 40, no. 10, pp. 1809-1823, 2002.

[8] J. Mittal and K. L. Lin, "Connecting carbon nanotubes using Sn," Journal of Nanoscience and Nanotechnology, vol. 13, no. 1, pp. 1-7, 2013.

[9] G. Lota, E. Frackowiak, J. Mittal, and M. Monthioux, "High performance supercapacitor from chromium oxide-nanotubes based electrodes," Chemical Physics Letters, vol. 434, no. 1-3, pp. 73-77, 2007.

[10] J. Mittal, M. Monthioux, H. Allouche, and O. Stephan, "Room temperature filling of single-wall carbon nanotubes with chromium oxide in open air," Chemical Physics Letters, vol. 339, no. 5-6, pp. 311-318, 2001.

[11] U. Wiedwald and P. Ziemann, "Preparation, properties and applications of magnetic nanoparticles," Beilstein Journal of Nanotechnology, vol. 1, pp. 21-23, 2010.

[12] D. Bahadur, J. Giri, B. B. Nayak et al., "Processing, properties and some novel applications of magnetic nanoparticles," Pramana, vol. 65, no. 4, pp. 663-679, 2005.

[13] Y.-J. Kang, J. Choi, C.-Y. Moon, and K. J. Chang, "Electronic and magnetic properties of single-wall carbon nanotubes filled with iron atoms," Physical Review B, vol. 71, no. 11, Article ID 115441, 2005.

[14] S. Karmakar, P. K. Tyagi, D. S. Misra, and S. M. Sharma, "Pressure-induced phase transitions in cobalt-filled multiwalled carbon nanotubes," Physical Review B, vol. 73, no. 18, Article ID 184119, 2006.

[15] S. Karmakar, S. M. Sharma, M. D. Mukadam, S. M. Yusuf, and A. K. Sood, "Magnetic behavior of iron-filled multiwalled carbon nanotubes," Journal of Applied Physics, vol. 97, no. 5, Article ID 054306, 2005.

[16] S. Karmakar, S. M. Sharma, P. V. Teredesai, and A. K. Sood, "Pressure-induced phase transitions in iron-filled carbon nanotubes: X-ray diffraction studies," Physical Review B, vol. 69, no. 16, Article ID 165414, p. 1, 2004.

[17] A. Leonhardt, M. Ritschel, R. Kozhuharova et al., "Synthesis and properties of filled carbon nanotubes," Diamond and Related Materials, vol. 12, no. 3-7, pp. 790-793, 2003.

[18] C. Guerret-Piécourt, Y. Le Bouar, A. Loiseau, and H. Pascard, "Relation between metal electronic structure and morphology of metal compounds inside carbon nanotubes," Nature, vol. 372, no. 6508, pp. 761-765, 1994.

[19] Y. Yosida, S. Shida, T. Ohsuna, and N. Shiraga, "Synthesis, identification, and growth mechanism of $\mathrm{Fe}, \mathrm{Ni}$, and Co crystals encapsulated in multiwalled carbon nanocages," Journal of Applied Physics, vol. 76, no. 8, pp. 4533-4539, 1994.

[20] P. M. Ajayan and S. Lijima, "Capillarity-induced filling of carbon nanotubes," Nature, vol. 361, no. 6410, pp. 333-334, 1993.

[21] P. J. F. Harris and S. C. Tsang, "A simple technique for the synthesis of filled carbon nanoparticles," Chemical Physics Letters, vol. 293, no. 1-2, pp. 53-58, 1998.

[22] T. Hayashi, S. Hirono, M. Tomita, and S. Umemura, "Magnetic thin films of cobalt nanocrystals encapsulated in graphite- like carbon," Nature, vol. 381, no. 6585, pp. 772-774, 1996.

[23] P. E. Nolan, D. C. Lynch, and A. H. Cutler, "Catalytic disproportionation of CO in the absence of hydrogen: encapsulating shell carbon formation," Carbon, vol. 32, no. 3, pp. 477-483, 1994.

[24] Z. J. Liu, Z. Y. Yuan, W. Zhou, Z. Xu, and L. M. Peng, "Controlled synthesis of carbon-encapsulated Co nanoparticles by CVD," Advanced Materials, vol. 13, no. 21, pp. 248-251, 2001.

[25] G. N. Glavee, K. J. Klabunde, C. M. Sorensen, and G. C. Hadjapanayis, "Borohydride reductions of metal ions. A new understanding of the chemistry leading to nanoscale particles of metals, borides, and metal borates," Langmuir, vol. 8, no. 3, pp. 771-773, 1992.

[26] C. A. Brown and V. K. Ahuja, "Catalytic hydrogenation. VI. The reaction of sodium borohydride with nickel salts in ethanol solution. P-2 nickel, a highly convenient, new, selective hydrogenation catalyst with great sensitivity to substrate structure," Journal of Organic Chemistry, vol. 38, no. 12, pp. 2226-2230, 1973. 

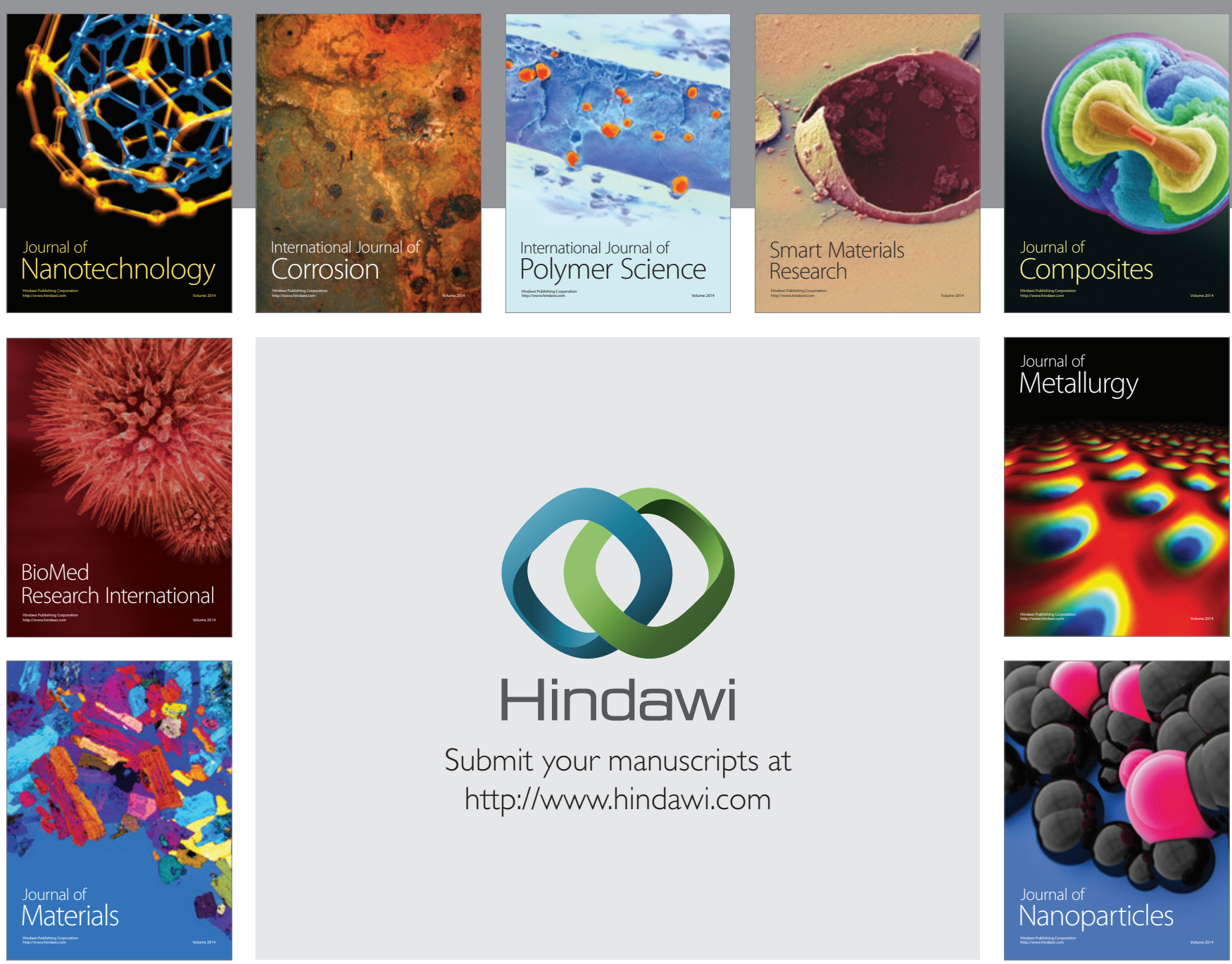

Submit your manuscripts at http://www.hindawi.com
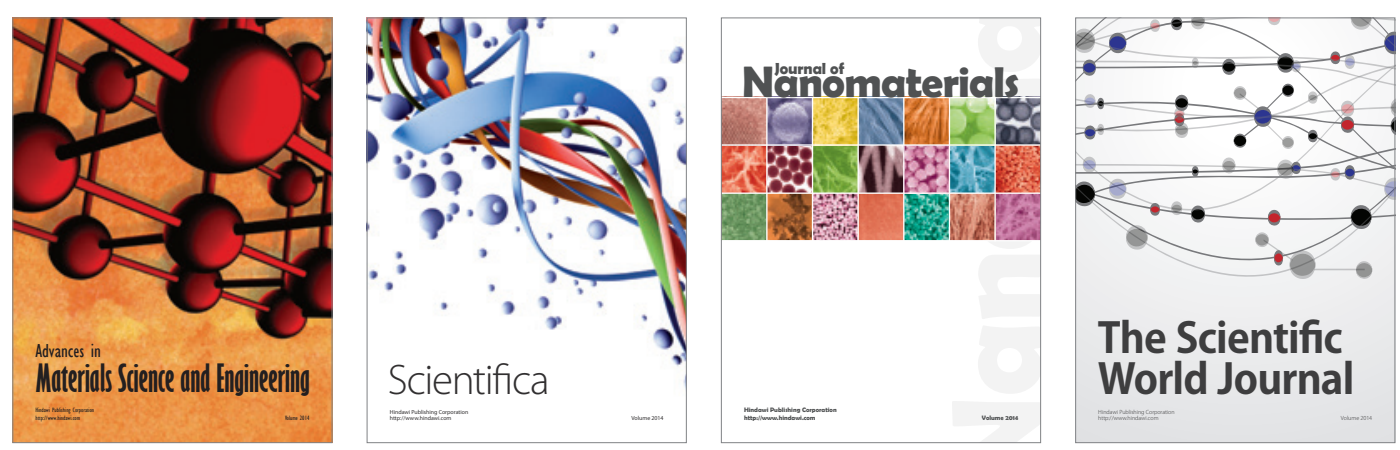

\section{The Scientific World Journal}
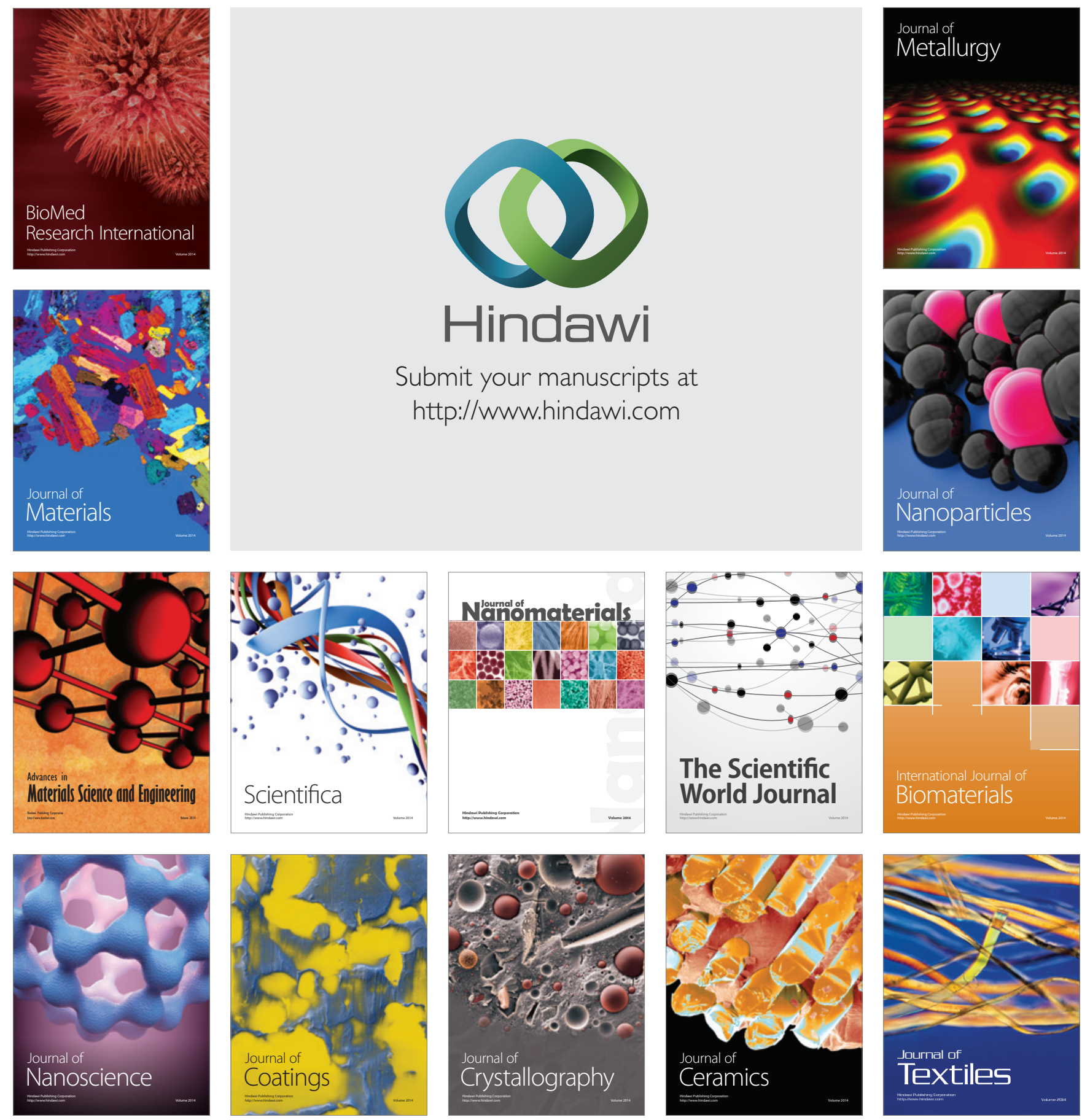